\title{
Research Paper: Developing the Persian Version of Infant-Toddler Meaningful Auditory Integration Scale
}

\author{
Akbar Darouie $^{1}$ (D), Mamak Joulaie ${ }^{2}$ (D), Farzaneh Zamiri Abdollahi ${ }^{* *}$ (D), Amy McConkey Robbins ${ }^{4}$ (D), Somayeh Zarepour² (D), Tayebeh Ahmadi² (D)
}

1. Department of Speech Therapy, University of Social Welfare and Rehabilitation Sciences, Tehran, Iran.

2. AVA Rehabilitation Center, Karaj, Iran.

3. Department of Audiology, School of Rehabilitation, Tehran University of Medical Sciences, Tehran, Iran.

4. Department of Otolaryngology, Head and Neck Surgery, Indiana University School of Medicine, Indiana, USA

\begin{tabular}{|c|c|}
\hline $\begin{array}{l}\text { Use yuur device to scan } \\
\text { and read the article online }\end{array}$ & Ceftat on Darouie A Joulaie M. Zamiri Abdollahi F Robbins AM Zarepour S, Ahmadi T Develoning the Persian Version \\
\hline 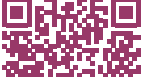 & $\begin{array}{l}\text { of Infant-Toddler Meaningful Auditory Integration Scale. Iranian Rehabilitation Journal. 2019; 17(1):53-60. http://dx.doi. } \\
\text { org/10.32598/irj.17.1.53 }\end{array}$ \\
\hline abyini & dol' http://dx.doi.org/10.32598/irj.17.1.53 \\
\hline
\end{tabular}

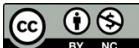

Article info:

Received: 13 Sep 2018

Accepted: 08 Jan 2019

Available Online: 01 Mar 2019

\section{Keywords:}

Hearing loss, Cochlear implants, Hearing aids, Infants

\section{ABSTRACT}

Objectives: Infant-Toddler Meaningful Auditory Integration Scale (IT-MAIS) is a useful too for the quantitative evaluation of auditory behaviors in different situations. The present study aimed to develop the Persian version of IT-MAIS.

Methods: There was 4 main steps in the translation and validation of the scale, as follows: forward translation, synthesis, backward translation, and expert committee discussion. Then, the final Persian version of the scale was analyzed in terms of reliability and validity. The scale was studied on the parents of 17 hearing impaired and 17 normal hearing children

Results: There was a significant difference in the mean score of scale between hearing impaired and normal hearing children $(\mathrm{P} \leq 0.001)$. The internal consistency of the items was satisfactory. The Cronbach's alpha for the overall score was 0.93 .

Discussion: This study suggested that IT-MAIS-F can be a reliable and valid tool for the evaluation of the auditory function of children. However, the sample size of the study was small. Thus, studies with larger sample sizes are recommended. In addition, test-retest reliability of the scale was not studied.

\section{* Corresponding Author:}




\section{Highlights}

- There are subjective and objective methods to evaluate hearing loss in infants and toddlers.

- It is difficult to monitoring auditory responses in infants and toddlers who have assistive hearing aids.

\section{Plain Language Summary}

A lot of children suffer from hearing loss or impairments. Many children have a hearing loss since birth or develop it during their first years of lives. There are several subjective and objective tests for early hearing loss diagnosis that help us to manage the disorder as early as possible. However, checking children's auditory responses after receiving hearing aid or cochlear implant is hard due to their lack of cooperation in behavioral tests. The Infant-Toddler Meaningful Auditory Integration Scale (IT-MAIS) is a useful tool for checking hearing-impaired infants and toddlers via an interview with their parents and can help us determine if everything is alright. This scale was not available in Farsi so this study was conducted to evaluate its Farsi version that was proved to be valid and reliable.

\section{Introduction}

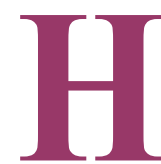

earing loss is a prevalent disorder among infants and toddlers. The average incidence rate of hearing loss in newborns in the USA is approximately 1.1 per 1000 infants [1]. This prevalence is higher in infants suffering from one or more risk factors for hearing impairment. The prevalence of hearing loss in neonates with low risk extends from $0.09 \%$ to $2.3 \%$; however, in the high-risk infants, it is estimated to range from $0.3 \%$ to $14.1 \%$. The prevalence rate of hearing loss is as high as $11 \%$ in neonates with very low birth weight [2]. Iran lacks a nationwide estimation about hearing loss prevalence; however, based on some studies, it seems to be highly prevalent especially due to the high rate of consanguinity in Iran $[3,4]$.

The severity of hearing loss can range from mild to profound and can be monaural or bilateral. Hearing loss, in general, has adverse effects on speech and language development. The negative consequences of hearing loss increase with the severity of hearing loss, the involvement of both ears, and prelingual hearing loss $[5,6]$. The first three years of infant's life (especially the first year) is a golden time for exposure to auditory stimuli as the brain is most plastic for learning speech and language skills [7, 8]. The rich language environment and perfect auditory access are vital components for a developing child [9].

To provide good auditory access, there is an absolute need for providing a suitable sensory aid (hearing aid or cochlear implant) as early as possible. Good auditory access is a key component prior to any successful auditory rehabilitation or early intervention [10]. Evaluating auditory access and auditory skills of infants and toddlers can be challenging. Their behavioral test results may be inconsistent [11]. In addition, pure tone audiometry and speech recognition tests in quiet overlook auditory function in real-world situations; thus, may not be good predictors of child's auditory behavior [12].

Infant-Toddler Meaningful Auditory Integration Scale (IT-MAIS) is useful for the quantitative evaluation of auditory behaviors in different situations. IT-MAIS (Zimmerman-Phillips 2000) is a Modification of the original scale (Meaningful Auditory Integration Scale; MAIS) [13]. This scale is actually a structured interview with parents. It consisted of 10 main probes that assess three areas: vocalization behavior; alertness to sounds; and deriving meaning from sound. For scoring, 0 (lowest) to 4 (highest) points can be designated to each probe. The time percentage spent by the child on auditory abilities is investigated and scored. Therefore, the maximum achievable score is 40 . There are 5 response options to each question including never, rarely, occasionally, frequently, and always. The total score (20 questions for 10 probes) is calculated, ultimately.

Since the introduction of IT-MAIS, numerous studies have used this scale for determining hearing aid benefits, cochlear implant candidacy and cochlear implant outcome measures. In general, it is considered as a useful tool for evaluating audiological outcomes in children younger than 3 years of age [14-21]. It is translated and validated in many languages including Arabic, Italian, Chinese, German, Polish, and British English [21-23]. 
IT-MAIS test-retest reliability, Intraclass Correlation Coefficient (ICC), internal consistency (Cronbach's alpha), and content validity (Pearson's correlation confident) were $0.92,0.89,26.84$ and 0.84 , respectively [13].

The present study aimed to translate and validate ITMAIS in Persian speakers. The forward-backward translation method was applied. This study was conducted with the assistance of one of the main developers of the original scale and under her official permission.

\section{Methods}

After contacting with the third author who is one of the main developers of the scale, and obtaining her permission, the scale was translated from English to Persian by 4 professionals including two audiologists and two speech-language pathologists (step 1: Forward translation). These professionals comprised the expert committee throughout the study. In translation, there was a need for some cultural adaptations such as changing the probes' examples. The translated scale was discussed with two audiologists and two speech-language pathologists familiar with the research method for improving these versions (step 2: Synthesis). After final approval, the resultant version was provided to a professional translator and a bilingual (Persian-English) speech-language pathologist who was not familiar with the original scale, to translate it into English (step 3: Backward translation). The expert committee compared the new backward translation with the original one to ensure that it has the same semantic value as the original scale (step 4: Expert committee discussion).

The translation was forwarded to the author and she approved the scale. Then, the Persian-IT-MAIS was distributed among 5 audiologists, 6 speech-language pathologists, and 5 mothers of hearing impaired children for evaluating its face validity. The explored factors included clarity, simplicity, and relevance. Their comments were taken into consideration and were crosschecked by the author. Finally, 17 Persian infants and toddlers with normal hearing (10 males and 7 females with a Mean \pm SD age of $28.29 \pm 7.37$ months) and 17 hearing aid user Persian infants and toddlers with a profound hearing loss (10 males and 7 females, with a Mean \pm SD age of $23.23 \pm 5.93$ months) were enrolled in the pilot study (step 5: testing the pre-final version).

Only children with native Persian speaking parents were enrolled. All the normal hearing children were recruited from those who had passed the universal newborn hearing screening and their hearing status were considered normal based on audiological documents. Moreover, children with hearing impairment risk factors based on the Joint Committee on Infant Hearing (JCIH) were excluded from the study.

Research ethics based on the Declaration of Helsinki were observed. All evaluations were non-invasive. Informed consent was obtained from the mothers of hearing-impaired children, and other subjects. In the normal hearing children, only 9 items out of total 10 probes of IT-MAIS were demonstrated. This was because the first item, 'is the child's vocal behavior affected while wearing his/her sensory aid (hearing aid or cochlear implant)?' was not included and inapplicable to the normal hearing children. Children with profound hearing loss had the auditory thresholds of $\geq 90 \mathrm{dBHL}$ in behavioral audiology tests and Auditory Brainstem Response (ABR) based on the records.

They did not have any additional disabilities. The test items were asked by the mothers as a structured interview. The Mean \pm SD age of children's mothers was $45.5 \pm 5$ years and all of them had at least 12 years of academic education. The interviewer was a trained speechlanguage pathologist with 16 years of experience in the field of auditory rehabilitation. The interviews were conducted in a room without distracters. The children's mothers had no time limit to think, ask questions and respond, during interviews.

The test terminology was altered based on the mothers' suggestions and the final version of the scale was formed. The three main areas of the scale (vocalization behavior; alertness to sounds; and deriving meaning from sound) were analyzed concurrently. Internal consistency indicates to what extend each item measures the same underlying construct. For this evaluation, the IT-MAIS-F scores in 17 normal hearing infants and toddlers were investigated.

\section{Results}

The Mann-Whitney U test was performed on items 2 to 10 of the scale, because probe 1 was only used in children with hearing loss. There was a significant difference $(\mathrm{P} \leq 0.001)$ between the two groups in all items (Table 1). Cronbach's alpha confident was applied for evaluating the internal consistency of the scale. Cronbach's alpha from 0.7 to 0.9 were considered in the range of acceptable internal consistency. The overall score Cronbach's alpha was 0.93 . The results of inter-item reliability were acceptable (Table 2). 
Table 1. Mann-Whitney U test for probes 2 to 10 of IT-MAIS-F

\begin{tabular}{|c|c|c|c|}
\hline & & Mean \pm SD & $\mathbf{P}$ \\
\hline \multirow{3}{*}{ Probe 2} & Profound & $3.00 \pm 1.22$ & \multirow{3}{*}{$\leq 0.001$} \\
\hline & & & \\
\hline & Normal & $4.00 \pm 0.00$ & \\
\hline \multirow{3}{*}{ Probe 3} & Profound & $2.71 \pm 1.16$ & \multirow{3}{*}{$\leq 0.001$} \\
\hline & & & \\
\hline & Normal & $4.00 \pm 0.00$ & \\
\hline \multirow{3}{*}{ Probe 4} & Profound & $2.12 \pm 1.16$ & \multirow{3}{*}{$\leq 0.001$} \\
\hline & & & \\
\hline & Normal & $4.00 \pm 0.00$ & \\
\hline \multirow{3}{*}{ Probe 5} & Profound & $2.53 \pm 1.17$ & \multirow{3}{*}{$\leq 0.001$} \\
\hline & & & \\
\hline & Normal & $4.00 \pm 0.00$ & \\
\hline \multirow{3}{*}{ Probe 6} & Profound & $2.35 \pm 1.16$ & \multirow{3}{*}{$\leq 0.001$} \\
\hline & & & \\
\hline & Normal & $4.00 \pm 0.00$ & \\
\hline \multirow{3}{*}{ Probe 7} & Profound & $2.29 \pm 0.10$ & \multirow{3}{*}{$\leq 0.001$} \\
\hline & & & \\
\hline & Normal & $4.00 \pm 0.00$ & \\
\hline \multirow{3}{*}{ Probe 8} & Profound & $2.44 \pm 1.36$ & \multirow{3}{*}{$\leq 0.001$} \\
\hline & & & \\
\hline & Normal & $4.00 \pm 0.00$ & \\
\hline \multirow{3}{*}{ Probe 9} & Profound & $2.41 \pm 1.06$ & \multirow{3}{*}{$\leq 0.001$} \\
\hline & & & \\
\hline & Normal & $4.00 \pm 0.00$ & \\
\hline \multirow{3}{*}{ Probe 10} & Profound & $2.47 \pm 1.12$ & \multirow{3}{*}{$\leq 0.001$} \\
\hline & & & \\
\hline & Normal & $4.00 \pm 0.00$ & \\
\hline
\end{tabular}

Iranian Rehabilitation Journal

Table 2. Internal consistency of IT-MAIS-F items

\begin{tabular}{ccc}
\hline Questiones & Scale Mean (If the Item Was Deleted) & Cronbach's Alpha (If the Item Was Deleted) \\
\hline Question 2 & 19.80 & 0.91 \\
\hline Question 3 & 19.38 & 0.94 \\
\hline Question 4 & 20.06 & 0.92 \\
\hline Question 5 & 19.63 & 0.92 \\
\hline Question 6 & 19.75 & 0.92 \\
\hline Question 7 & 19.81 & 0.91 \\
\hline Question 8 & 19.63 & 0.91 \\
\hline Question 9 & 19.69 & 0.91 \\
\hline Question 10 & 19.50 & 0.92 \\
\hline
\end{tabular}




\section{Discussion}

In this study, IT-MAIS-F was translated and validated into Persian and examined on 17 hearing impaired and 17 normal hearing children. The results revealed that ITMAIS-F is a reliable scale applicable in Persian speaking children. In face validity examination, all items were clear, simple, understandable, and relevant to the scale initial aim. All of the studied children's' mothers were comfortable answering the probes. Based on the experts' report, the scale was easy to administer and its completion took about 20 to 30 minutes.

IT-MAIS-F internal consistency was acceptable ( $\alpha=0.93$ for the total score and $0.92,0.91$ for detection and recognition subscales, respectively). In a study on the development of Italian IT-MAIS, internal consistency satisfactorily extended from $\alpha=0.87$ for the detection to $\alpha=0.92$ for the recognition category [24]. In another study on the IT-MAIS on a Chinese population, Cronbach's alpha was obtained as 0.96 for the total score. Zhong et al. studied the reliability and validity of the Chinese version of IT-MAIS in 300 children with a cochlear implant and Cronbach's alpha coefficient equal to 0.836 for the total score [13].

These results suggest that this scale is a reliable and valid tool. The internal consistency and item reliability of the Chinese version of IT-MAIS was comparable to the German, Polish, and British English versions of ITMAIS scale. These similar results among different cultures and languages might be attributable to the same development course of the early pre-lingual auditory function in all infants. All items of the original scale were kept in the cross-language version of IT-MAIS [21].

In the present study, there was a significant difference between the mean scores of the scale in normal hearing and hearing impaired children. The significant differences in IT-MAIS scores in children with profound hearing loss and in normal hearing children suggest that the ITMAIS-F could potentially be a useful tool in assessing auditory performance and monitoring sensory device benefits in hearing impaired children. This result is in agreement with the Italian version of IT-MAIS [24].

IT-MAIS can clarify normative auditory skill development and be used as an outcome measurement tool for the evaluation of early hearing intervention, hearing aid and cochlear implant [14]. IT-MAIS is the most frequently used parental questionnaire in the USA, and widely used in different parts of the world to help determine cochlear implant candidacy and monitoring listen- ing development after cochlear implant surgery in children with hearing loss [24]. This scale has been widely used in assessing the progress of auditory performance in very young children [25].

This study suggested that IT-MAIS-F can be a reliable and valid tool for the evaluation of the auditory function of children. However, the sample size of the study was small. Studies with larger sample sizes are recommended on this subject. In addition, test-retest reliability of the scale was not studied.

\section{Conclusion}

The Persian versions of IT-MAIS (IT-MAIS-F) has a high internal consistency and validity which make it a reliable and useful tool for evaluating auditory functions among infants and toddlers.

\section{Ethical Considerations}

\section{Compliance with ethical guidelines}

This study followed ethical guidelines of Helsinki declarations.

Funding

This research did not receive any specific grant from funding agencies in the public, commercial, or not-forprofit sectors.

\section{Authors contributions}

Conceptualization: Akbar Darouie, Mamak Joulaie, Farzaneh Zamiri Abdollahi, Tayebeh Ahmadi; Methodology: Akbar Darouie, Mamak Joulaie, Farzaneh Zamiri Abdollahi, Tayebeh Ahmadi; Software: Akbar Darouie, Mamak Joulaie, Farzaneh Zamiri Abdollahi, Amy McConkey Robbins, Tayebeh Ahmadi; Validation: Akbar Darouie, Mamak Joulaie, Farzaneh Zamiri Abdollahi, Amy McConkey Robbins, Tayebeh Ahmadi; Formal analysis: Mamak Joulaie, Farzaneh Zamiri Abdollahi, Amy McConkey Robbins; Investigation: Mamak Joulaie, Farzaneh Zamiri Abdollahi, Somayeh Zarepour; Resources: Mamak Joulaie, Farzaneh Zamiri Abdollahi, Somayeh Zarepour; Data curation: Somayeh Zarepour; Writing-original draft preparation: Mamak Joulaie, Farzaneh Zamiri Abdollahi, Amy McConkey Robbins; Writing-review \& editing: Mamak Joulaie, Farzaneh Zamiri Abdollahi; Visualization: Mamak Joulaie, Farzaneh Zamiri Abdollahi; Supervision: Akbar Darouie; and Project administration: Akbar Darouie. 


\section{Conflict of interest}

The authors declare no conflict of interest.

\section{Acknowledgements}

We sincerely thank the mothers of hearing-impaired children, who participated in the current study.

\section{References}

[1] Mehra S, Eavey RD, Keamy Jr DG. The epidemiology of hearing impairment in the United States: Newborns, children, and adolescents. Otolaryngology-Head and Neck Surgery. 2009; 140(4):461-72. [DOI:10.1016/j.otohns.2008.12.022] [PMID]

[2] Botelho FA, Bouzada MCF, Resende LMd, Silva CFX, Oliveira EA. Prevalence of hearing impairment in children at risk. Brazilian Journal of Otorhinolaryngology. 2010; 76(6):739-44 [DOI:10.1590/S1808-86942010000600012] [PMID]

[3] Ajallouyan M, Radfar S, Nouhi S, Tavallaie SA, Amirsalari S, Yousefi J, et al. Consanguinity among parents of Iranian deaf children. Iranian Red Crescent Medical Journal. 2016, 18(11):22-38. [DOI:10.5812/ircmj.22038] [PMID] [PMCID]

[4] Amini SR, Kamali M. Consanguineous marriage among the parents of hearing impaired students in Mashhad. Iranian Rehabilitation Journal. 2010; 8(2):36-9.

[5] Coulter D, Thomson V. The Colorado newborn hearing screening project: Effects on speech and language development for children with hearing loss. Journal of Perinatology. 2000; 20(1):S132-7.

[6] Stelmachowicz PG, Pittman AL, Hoover BM, Lewis DE, Moeller MP. The importance of high-frequency audibility in the speech and language development of children with hearing loss. Archives of Otolaryngology-Head \& Neck Surgery. 2004; 130(5):556-62. [DOI:10.1001/archotol.130.5.556] [PMID]

[7] Kral A. Auditory critical periods: A review from system's perspective. Neuroscience. 2013; 247:117-33. [DOI:10.1016/j. neuroscience.2013.05.021] [PMID]

[8] Purves D, Augustine G, Fitzpatrick D, Katz L, LaMantia A, McNamara J, et al. The development of language: A critical period in humans. In: Purves D, Augustine GJ, Fitzpatrick D, Katz LC, LaMantia AS, McNamara JO, et al., editors. Neuroscience. Sunderland: Sinauer Associates; 2001.

[9] Harrison M, Page TA, Oleson J, Spratford M, Berry LU, Peterson B, et al. Factors affecting early services for children who are hard of hearing. Language, Speech, and Hearing Services in Schools. 2016; 47(1):16-30. [DOI:10.1044/2015 LSHSS-14-0078] [PMID] [PMCID]

[10] Martin-Prudent A, Lartz M, Borders C, Meehan T. Early intervention practices for children with hearing loss: Impact of professional development. Communication Disorders Quarterly. 2016; 38(1):13-23. [DOI:10.1177/1525740115597861]
[11] Bonino AY, Leibold LJ. Behavioral assessment of hearing in 2 to 4 year-old children: A two-interval, observerbased procedure using conditioned play-based responses. Journal of Visualized Experiments. 2017; 119(54788):1-7. [DOI:10.3791/54788]

[12] Council NR. Hearing loss: Determining eligibility for social security benefits. Washington: National Academies Press; 2004

[13] Zhong Y, Xu T, Dong R, Lyu J, Liu B, Chen X. The analysis of reliability and validity of the IT-MAIS, MAIS and MUSS International Journal of Pediatric Otorhinolaryngology. 2017; 96:106-10. [DOI:10.1016/j.ijporl.2017.03.006] [PMID]

[14] Bagatto MP. Development and evaluation of an audiological outcome measure guideline for use with infants, toddlers, and preschool children [PhD. dissertation]. Ontario: The University of Western Ontario; 2012.

[15] Ben Itzhak D, Greenstein T, Kishon Rabin L. Parent report of the development of auditory skills in infants and toddlers who use hearing aids. Ear and Hearing. 2014; 35(6):262-71. [DOI:10.1097/AUD.0000000000000059] [PMID]

[16] Kishon-Rabin L, Kuint J, Hildesheimer M, Ari-Even Roth D. Delay in auditory behaviour and preverbal vocalization in infants with unilateral hearing loss. Developmental Medicine \& Child Neurology. 2015; 57(12):1129-36. [DOI:10.1111/ dmcn.12812] [PMID]

[17] Liang S, Soli SD, Zheng Y, Li G, Meng Z. Initial classification of pediatric hearing impairment using behavioral measures of early prelingual auditory development. International Journal of Audiology. 2016; 55(4):224-31. [DOI:10.3109/14992 027.2015.1120891] [PMID]

[18] Peterson A, Shallop J, Driscoll C, Breneman A, Babb J, Stoeckel R, et al. Outcomes of cochlear implantation in children with auditory neuropathy. Journal of the American Academy of Audiology. 2003; 14(4):188-201. [PMID]

[19] Pinto ESM, Lacerda CBdF, Porto PRC. Comparison between the IT-MAIS and MUSS questionnaires with videorecording for evaluation of children who may receive a cochlear implantation. Revista Brasileira de Otorrinolaringologia 2008; 74(1):91-8. [DOI:10.1590/S0034-72992008000100015] [PMID]

[20] Robbins AM, Koch DB, Osberger MJ, Zimmerman-Phillips $\mathrm{S}$, Kishon-Rabin L. Effect of age at cochlear implantation on auditory skill development in infants and toddlers. Archives of Otolaryngology-Head \& Neck Surgery. 2004; 130(5):570-74 [DOI:10.1001/archotol.130.5.570] [PMID]

[21] Zheng Y, Soli SD, Wang K, Meng J, Meng Z, Xu K, et al A normative study of early prelingual auditory development. Audiology and Neurotology. 2009; 14(4):214-22 [DOI:10.1159/000189264] [PMID]

[22] Kishon-Rabin L, Taitelbaum R, Elichai O, Maimon D, Debyiat D, Chazan N. Developmental aspects of the IT-MAIS in normal-hearing babies. The Journal of Speech and Hearing Disorders. 2001; 23(1):12-22.

[23] Weichbold V, Anderson I, D'haese P. Validation of three adaptations of the Meaningful Auditory IntegrationScale (MAIS) to German, English and Polish. International Journal of Audiology. 2004; 43(3):156-61. [DOI:10.1080/14992020400050021] [PMID] 
[24] Cavicchiolo S, Mozzanica F, Guerzoni L, Murri A, Dall'Ora I, Ambrogi F, et al. Early prelingual auditory development in Italian infants and toddlers analysed through the Italian version of the Infant-Toddler Meaningful Auditory Integration Scale (IT-MAIS). European Archives of Oto-Rhino-Laryngology. 2018; 275(2):615-22. [DOI:10.1007/s00405-017-4847-6] [PMID]

[25] Vlastarakos PV, Proikas K, Papacharalampous G, Exadaktylou I, Mochloulis G, Nikolopoulos TP. Cochlear implantation under the first year of age-The outcomes. A critical systematic review and meta-analysis. International Journal of Pediatric Otorhinolaryngology. 2010; 74(2):119-26. [DOI:10.1016/j.ijporl.2009.10.004] [PMID] 
This Page Intentionally Left Blank 